\title{
Taguchi's Parameter Design in Industrial Practice - Statistical Aspects
}

\author{
Petra Rodiga-Laßnig and Klemens Fuchs \\ Institute for Applied Statistics and Systems Analysis \\ Joanneum Research
}

\begin{abstract}
Experimental design had little importance in industry until Taguchi's ideas changed the approach to quality completely. Nowadays, it is well known that quality has to be designed "into" products and cannot be reached by inspecting and sorting before delivering. The aim of Taguchi's Parameter Design is to create robust products insensitive to manufacturing processes and more over insensitive to noise (or uncontrollable) factors in the customer's environment by finding the most important controllable factors. In this real case study Taguchi's ideas were applied to a rather complex personal care product to improve its performance.
\end{abstract}

Zusammenfassung: Statistische Versuchsplanung hatte in der industriellen Praxis eine eher geringe Bedeutung bevor durch Taguchi der Begriff "Qualität” einen neuen Stellenwert erlangte. Heutzutage ist es selbstverständlich, daß Qualität in ein Produkt "hinein" entwickelt werden muß bzw. daß Qualität nicht durch eine Endprüfung vor Auslieferung an den Kunden erreicht werden kann. Ziel des Parameter Designs von Taguchi ist, robuste Produkte zu entwickeln, die möglichst unbeeinflußt von Produktionsbedingungen und in weiterer Folge auch unbeeinflußt von unkontrollierbaren Rauschfaktoren während der Nutzungsdauer durch den Kunden sind. Erreicht wird dies durch die Identifikation der wichtigsten, kontrollierbaren Faktoren. In diesem Beispiel aus der industriellen Praxis wurden die Methoden Taguchis bei der Entwicklung eines komplexen Personal Care Produktes zur Leistungsverbesserung angewandt.

Keywords: Taguchi Method; Unreplicated Design; Fractional Factorial Design.

\section{Introduction}

Although experimental design is well known and widely used in agricultural and biological sciences, it did not become a lasting engineers' tool in industrial practice. For the engineers the methods seemed to be too 'mathematical' and not appropriate to be applied to the development and design of technical products. Nowadays, the situation changed because the companies are forced to produce best quality in shortest possible periods and the smallest tolerable risk to stand the continuous growing competition on the international market. Quicker, better, cheaper is the way to success. So quality control, quality improvement-quality in general-rates high. Instead of inspecting and sorting before delivering it is necessary to keep the production process under control from the very beginning. Quality control charts and process capability indices are statistical methods 
used for the on-line process control. Moreover it is necessary to design the quality "into" products where several methods of experimental designs are known.

\section{Taguchi - a Modern Method of Experimental Design}

The modern methods of experimental design include the methods of Taguchi as well as those of Shainin and genetic algorithms. Especially Taguchi's new philosophy and his easy applicable methods are the reason for his world wide success in industry. Usually in industrial practice every performance characteristic has a target value $\mathrm{T}$ and specification limits consisting of an upper and a lower specification limit (LSL, USL). Observations falling inside these limits are okay while observations falling outside the specification limits mean scrap or rework.

The most important catchword in Taguchi's philosophy is the loss function which gives us a completely new look at quality in general (Figure 1).

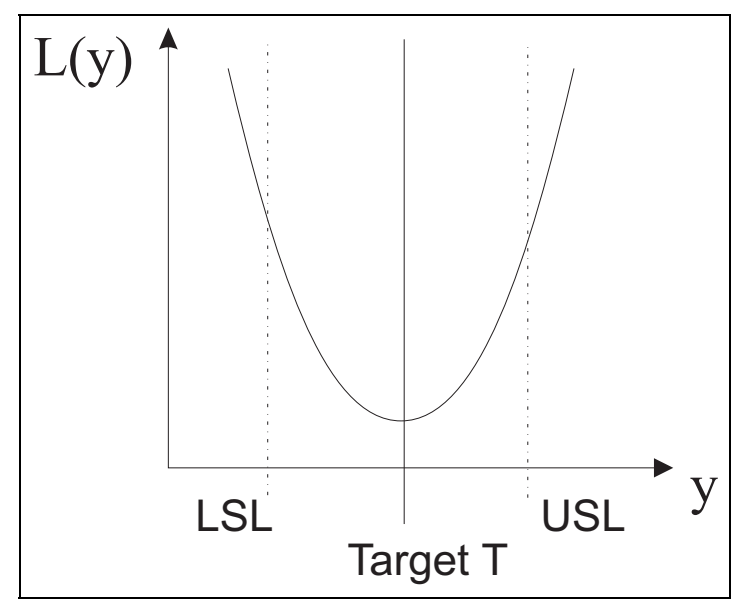

Figure 1: Loss Function

With this quadratic loss function big deviations from the target value are more panelized than small deviations. The new aspect is that it is not enough to produce within the specification limits but it is necessary to try to minimize the variation around the target value. Minimizing the variation around the target value leads to robust processes and robust products. Robust means that the process or product works well under uncontrollable conditions being insensitive to noise factors.

\section{Taguchi's Design of Experiments}

Taguchi's experimental concept consists of three parts, the system design, the parameter design, and the tolerance design (Taguchi, 1988). In the system design engineering and scientific know how is used. In the parameter design specific values for system parameters are determined trying to minimize the variation caused by uncontrollable factors. Whereas, in the tolerance design the best tolerances for the parameters are determined. This means setting tolerances for sensitive components and opening tolerances for less important components. 
To find out the most important components and the best setting for those components Taguchi proposes the orthogonal arrays prescribing the number of necessary combinations. To use the orthogonal array the engineers just have to follow a kind of step by step program which makes it easy for them to apply and to learn about experimental design in general (Krottmaier, 1990). First it is necessary to consider the controllable factors which can be influenced by the engineers and uncontrollable factors which can hardly be influenced or are very expensive to be influenced. Next step is to consider the levels for each of the factors in the experiment. Afterwards the engineer is able to choose one for the controllable and one for the uncontrollable factors out of all orthogonal arrays. For each array there exits a list of linear graphs which help to assign the factors to the columns in the array and to consider possible interactions. After running the experiment, Taguchi proposes the signal to noise ratio for the data analysis (Montgomery, 1991).

Analyzing Taguchi's orthogonal arrays it can be seen that they are not new designs but a special group of the fractional factorial with 2 levels. Instead of using ' + ' for the high level ' 2 ' is used and instead of using '-' ' 1 ' is used. Moreover, they are of resolution III. This means that every main effect is aliased with a two factor interaction. This property may cause misleading interpretation.

\section{Practical Problem - Design and Development of an Elec- tric Razor}

An electric shaver is a complex product consisting of more than fifty components like the foil, the razor blade, different system parameters like the engine etc. The advantages of electric razors is that they allow a very quick and handy shaving. But shaving on dry skin may cause painful skin irritation.

To reach the best shaving result (a maximum smoothness and a minimum skin irritation) it is necessary to find out the most important components and the best settings for those components. The engineers decided to use experimental design, on the one hand to improve the product's performance and on the other hand to learn about the very popular methods of Taguchi.

\section{Taguchi's System Design}

Using an Ishikawa-diagram (Figure 2) the engineers tried to find out about what kind of response variables describe an optimal shaving and what kind of components on the electric shaver may have an influence on this response variables. Beside the main response variables smoothness and skin irritation the engineers decided to include other response variables like the shaving time, the handling of problematic zones etc. in the investigation. From all potential components influencing the response variables eleven were chosen to be relevant. They are marked with bold letters in the Ishikawa-diagram.

Next step was to establish the experimental program which looked in detail as follows:

To get a representative sample of the male population it is necessary to take into account different ages and different kinds of beard colors. Therefore twenty men of three age categories (young, middle aged, old) and of five color types (blonde, brown, black, 


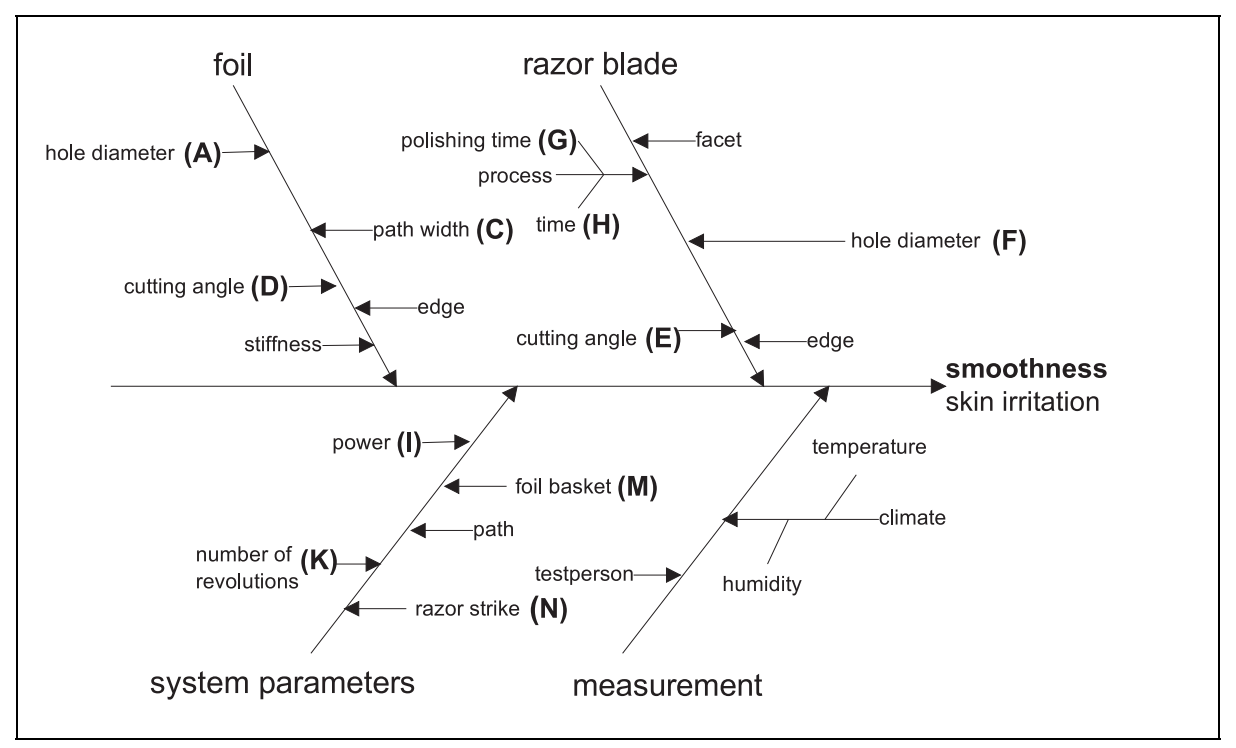

Figure 2: Ishikawa-diagram

red, grey) were chosen as test persons. The sample size ( $n=20$ persons) represented the maximum bearable expense.

Every person had to shave the one side of the face with a shaver $\mathrm{R}$ and the other side with a shaver X (block design). The shaving time (sec.) for every side was measured by the test manager. After shaving the test person rated the smoothness with school marks (1 for best and 5 for worst) and the test manager rated the skin irritation of every side also with school marks ( 1 for no skin irritation and 5 for bigger reddish spots on the skin). Beside all these subjective ratings there was also an objective rating for the smoothness. The day after the test person had to come again and the length of the stubbles $(\mu m)$ was measured. Every test person had to come in fact twice for one run.

Beside the fact that a block design reduces the variability there are two other benefits:

For the test persons the subjective rating is easier.

The comparison with the market leader can be included in the investigation.

As the following section will show 16 different shavers were constructed and used in comparison with the market leader. The experimentation period took more than three months (twenty men using 16 shavers in comparison with the market leader.) After fixing the two main response variables and the eleven most important components the engineers used Taguchi's parameter design to find out which are the most important ones.

\section{Taguchi's Parameter Design}

In general Taguchi's parameter design distinguishes between controllable and not controllable factors. For each factor's group a kind of fractional factorial design called orthogonal array is used. For the assignment of the factors Taguchi proposes linear graphs. The following section shows in detail how this works. 
Since all eleven components the engineers chose were controllable an appropriate orthogonal array was to be found. An orthogonal array $L_{16}$ (Figure 3 ) is for analyzing at most 15 factors, so the eleven factors and two two-factor-interactions can be investigated needing only 16 combinations. For the assignment of the factors $\mathrm{A}, \ldots, \mathrm{N}$ to the columns of the $L_{16}$ table linear graphs are used. For all orthogonal arrays Taguchi proposes a list of linear graphs (Taguchi, 1988).

\begin{tabular}{|c|c|c|c|c|c|c|c|c|c|c|c|c|c|c|c|}
\hline & $\mathbf{D}$ & $\bar{F}$ & $T$ & $E$ & $\mathrm{H}$ & C & & $\bar{K}$ & M & $\mathbf{N}$ & G & $\bar{A}$ & & $\mathbf{G H}$ & EG \\
\hline & 1 & 2 & 3 & 4 & 5 & 6 & 7 & 8 & 9 & 10 & 11 & 12 & 13 & 14 & 15 \\
\hline R1 & 1 & 1 & 1 & 1 & 1 & 1 & 1 & 1 & 1 & 1 & 1 & 1 & 1 & 1 & 1 \\
\hline R2 & 1 & 1 & 1 & 1 & 1 & 1 & 1 & 2 & 2 & 2 & 2 & 2 & 2 & 2 & 2 \\
\hline R3 & 1 & 1 & 1 & 2 & 2 & 2 & 2 & 1 & 1 & 1 & 1 & 2 & 2 & 2 & 2 \\
\hline R4 & 1 & 1 & 1 & 2 & 2 & 2 & 2 & 2 & 2 & 2 & 2 & 1 & 1 & 1 & 1 \\
\hline R5 & 1 & 2 & 2 & 1 & 1 & 2 & 2 & 1 & 1 & 2 & 2 & 1 & 1 & 2 & 2 \\
\hline R6 & 1 & 2 & 2 & 1 & 1 & 2 & 2 & 2 & 2 & 1 & 1 & 2 & 2 & 1 & 1 \\
\hline R7 & 1 & 2 & 2 & 2 & 2 & 1 & 1 & 1 & 1 & 2 & 2 & 2 & 2 & 1 & 1 \\
\hline R8 & 1 & 2 & 2 & 2 & 2 & 1 & 1 & 2 & 2 & 1 & 1 & 1 & 1 & 2 & 2 \\
\hline R9 & 2 & 1 & 2 & 1 & 2 & 1 & 2 & 1 & 2 & 1 & 2 & 1 & 2 & 1 & 2 \\
\hline R10 & 2 & 1 & 2 & 1 & 2 & 1 & 2 & 2 & 1 & 2 & 1 & 2 & 1 & 2 & 1 \\
\hline R11 & 2 & 1 & 2 & 2 & 1 & 2 & 1 & 1 & 2 & 1 & 2 & 2 & 1 & 2 & 1 \\
\hline R12 & 2 & 1 & 2 & 2 & 1 & 2 & 1 & 2 & 1 & 2 & 1 & 1 & 2 & 1 & 2 \\
\hline R13 & 2 & 2 & 1 & 1 & 2 & 2 & 1 & 1 & 2 & 2 & 1 & 1 & 2 & 2 & 1 \\
\hline R14 & 2 & 2 & 1 & 1 & 2 & 2 & 1 & 2 & 1 & 1 & 2 & 2 & 1 & 1 & 2 \\
\hline R15 & 2 & 2 & 1 & 2 & 1 & 1 & 2 & 1 & 2 & 2 & 1 & 2 & 1 & 1 & 2 \\
\hline $\mathrm{R} 16$ & 2 & 2 & 1 & 2 & 1 & 1 & 2 & 2 & 1 & 1 & 2 & 1 & 2 & 2 & 1 \\
\hline
\end{tabular}

Figure 3: $L_{16}$ Table

Out of all possible linear graphs for a $L_{16}$ table the engineers chose the one in Figure 4 . According to Taguchi circles in the linear graph represent main effects and lines between circles represent the interaction between them. The numbers of the circles and lines correspond to the columns in the orthogonal array which makes it easy to assign the factors to the columns. If a two factor interaction is negligible or even impossible in the engineers' opinion the corresponding line can be set as a circle and a main effect can be put on it.

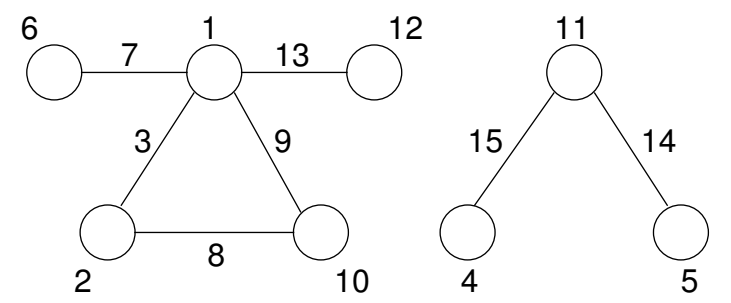

Figure 4: Original Linear Graph

The interesting effects were eleven main effects and two two-factor interactions. So the linear graph in Figure 4 was rearranged and is shown in Figure 5. Comparing it with the original one the lines 3, 8, 9 became circles, that means main effects.

Analyzing 13 effects altogether means that two columns in the $L_{16}$ table stay free. But there was a technical restriction concerning the foil. The steel foil could not be varied in 


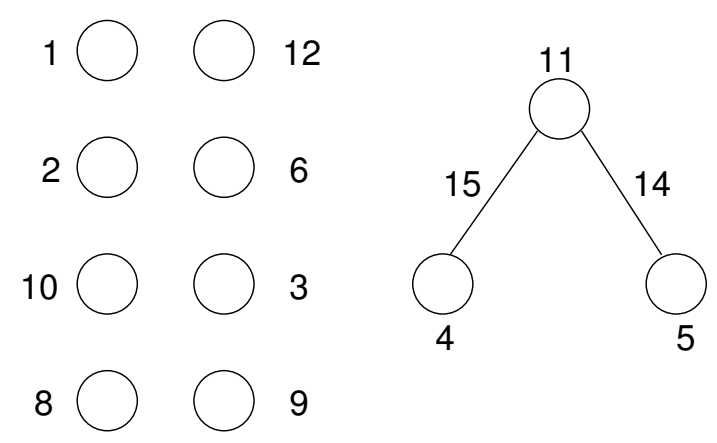

Figure 5: Rearranged Linear Graph

thickness and wideness like the nickel foil. So the lower half of the columns 6 and 12 are not available and must be deleted. This leads to the fact that the columns 6 and 7 as well as 12 and 13 have the same upper half and so the upper half of 7 and 13 must be deleted too (Figure 3).

For the experiments 16 shavers $R_{j}, j=1, \ldots, 16$, according to the $L_{16}$ table (Figure 3 ) were constructed. Every test person used each of these 16 shavers once. According to the experimental program one side of the face was shaved with a combination $R_{j}$ and the other with 16 uniform comparative shavers $X_{j}, j=1, \ldots, 16$.

\section{Statistical Critique of the Engineers' Taguchi Design}

Analyzing the $L_{16}$ orthogonal array it can be seen that this is not a new kind of design but a fractional factorial design for analyzing 15 factors with 2 levels. Since it is of resolution III, it is well known that this property may cause misleading interpretation. The significance of main effects may be caused by the main effect or the aliased two factor interaction.

The linear graphs make the assigning of the factors to the columns in the table simple, but they also disguise the aliasing structure. It is hard to get information about effects not used expressly in the array. So it is not easy to find out which effects have the same estimators. This situation makes it nearly impossible to check significances with principles like the principle of effect sparsity and the principle of effect heredity.

From the statistician's view it would have been better to over-think the number of selected factors. On the one hand the technical restriction caused by the foil resulted in loosing two columns in the design. It would have been better to skip the factors thickness and wideness of the foil in this first screening design and analyze their influence in a sequential design. Moreover for a first screening design the 2 two-factor-interactions would have been skipped. Without the two interactions and the factors thickness and wideness of the foil there are 9 factors left for a first design. A fractional factorial design with resolution IV $\left(2^{9-4}\right)$ for 9 factors needs in fact 32 combinations, which would have exceed any possible expense.

For a first design analyzing 9 factors a $2^{9-5}$ fractional factorial design would have been a good choice. It needs 16 combinations. The aliasing structure is defined by the following defining relation $I= \pm A B C E$. The design may be generated by

$$
E= \pm A B C \text {, }
$$




$$
\begin{aligned}
& F= \pm B C D, \\
& G= \pm A C D, \\
& H= \pm A B D, \\
& J= \pm A B C D .
\end{aligned}
$$

Since this design is of resolution III the main effects are aliased with two-factorinteractions and higher interactions and the two-factor-interactions are aliased with each other and higher interactions, it is important to know which two-factor-interactions do have the same estimators as the main effects.

$$
\begin{aligned}
& \mathrm{A}=\mathrm{FJ} \\
& \mathrm{B}=\mathrm{GJ} \\
& \mathrm{C}=\mathrm{HJ} \\
& \mathrm{D}=\mathrm{EJ} \\
& \mathrm{F}=\mathrm{AJ} \\
& \mathrm{G}=\mathrm{BJ} \\
& \mathrm{H}=\mathrm{CJ} \\
& \mathrm{J}=\mathrm{DE}=\mathrm{AF}=\mathrm{BG}=\mathrm{CH}
\end{aligned}
$$

The most interesting 2 two-factor-interactions are 'GH' and 'EG' . From above it is obvious that neither 'GH' nor 'EG' are aliased with main effects, but with other twofactor-interactions.

$\mathrm{GH}=\mathrm{AE}=\mathrm{BC}=\mathrm{DF}$

$\mathrm{EG}=\mathrm{AH}=\mathrm{BD}=\mathrm{CF}$

Although the interaction effects 'GH' and 'EG' are not explicitly in the design they can be estimated as usual in the analysis of variance.

Knowing the aliasing structure in detail makes the interpretion of significant effects more confident. Moreover the principle of effect heredity could have been used, which says that two factor interactions are usually significant if at least one corresponding main effect is significant. Based on the results of this first design there would have been the possibility of a design projection (Montgomery, 1991).

\section{Data Analysis}

After about three months of experimentation there was a vast amount of data available. The engineers' team decided to take professional help from a statistician to analyze the data. Explorative data analysis showed large variability in the data in general.

So the first step was to find out what possible reasons for that can be found. With the help of the test manager we found the most important ones:

$\checkmark$ the long period of experimentation with an extreme change of temperature and humidity because the experiments started in March and stopped in July,

$\downarrow$ the replacement of persons because of illness and holidays,

and a kind of learning effect among the test persons during the experimentation period. 
Our first approach to analyze the data was using the analysis of variance. The experimental error estimated by 20 observations per cell was rather big and no significance could be detected. So we decided to reduce the big variability by calculating one mean for each combination $R_{j}$. This meant that we built a kind of an "average test person". Taking for example the response 'objective rating for the smoothness' for every shaver combination $R_{j}, j=1, \ldots, 16$, the mean $\bar{x}_{j}, j=1, \ldots, 16$ was calculated

$$
\bar{x}_{j}=\frac{1}{2 m n} \sum_{1 \leq l \leq m} \sum_{1 \leq k \leq 2} \sum_{1 \leq i \leq n} y_{i k l j}
$$

where

$$
\begin{aligned}
& i=1, \ldots, n \text { : number of measured hairs }(\mu m) \\
& k=1,2: \text { left, right side } \\
& l=1, \ldots, m: \text { number of persons }
\end{aligned}
$$

If there is only one observation for each combination available this is called a single replicate or an unreplicate design. In this case there is no estimation for the experimental error. There are several possibilities to overcome that problem.

Half Normal Plots (Daniels, 1959; Zahn, 1975a,b) are used to get a quick impression which effects are significant and which are not. Beside this graphical method the Pseudo Standard Error (PSE) (Lenth, 1989) can be used for estimating the unknown true experimental error taking the risk of underestimation. Another approach is pooling high order interactions taking the risk of under- or overestimating the true experimental error. Due to the complex aliasing structure of the actual design pooling high order interactions seemed not to be a satisfying way to go.

\section{Results}

To identify the significant factors the estimators for the effects (S) as well as the PSE were calculated and as a graphical aid the half normal plots were used. As an example the results for the response 'objective rating for the smoothness' are shown in the following Table 1.

From the half normal plot Figure 6 three significant effects can be identified. ' $C$ ', ' $\mathrm{E}$ ' and ' $\mathrm{H}$ ' are lying off an imaginary line defined by the origin and the median of the contrasts while all the other factors are falling along this line. Analyzing the estimators of the effects in relation to PSE it is obvious that the ratio exceeds the critical value $t_{0.975, d}$ where $d=\frac{q}{3}$ ( $q$ is the number of contrasts) (Zahn, 1975b). So 'C', 'E' and ' $\mathrm{H}$ ' are statistically significant unequal to zero and can be interpreted as the most important factors concerning the response variable 'objective smoothness'.

\section{Conclusion}

As the statistical results also underlined the technical know how a confirmation experiment was planned. For this run the factors ' $\mathrm{C}$ ', ' $\mathrm{E}$ ' and ' $\mathrm{H}$ ' were set on the better setting and all the other non significant factors were set on the cheaper or easier to handle setting 


\begin{tabular}{|c|c|}
\hline factor & $\mathrm{S}$ \\
\hline \hline $\mathrm{N}$ & 1.69 \\
\hline $\mathrm{D}$ & 1.86 \\
\hline $\mathrm{G}$ & 2.02 \\
\hline $\mathrm{EG}$ & 2.91 \\
\hline $\mathrm{I}$ & 3.18 \\
\hline $\mathrm{F}$ & 3.31 \\
\hline $\mathrm{K}$ & 5.14 \\
\hline $\mathrm{A}$ & 5.57 \\
\hline $\mathrm{M}$ & 5.73 \\
\hline $\mathrm{HG}$ & 7.07 \\
\hline $\mathrm{H}$ & 14.65 \\
\hline $\mathrm{E}$ & 15.99 \\
\hline $\mathrm{C}$ & 19.42 \\
\hline \hline $\mathrm{PSE}$ & 4.77 \\
\hline
\end{tabular}

Table 1: Table of Contrasts

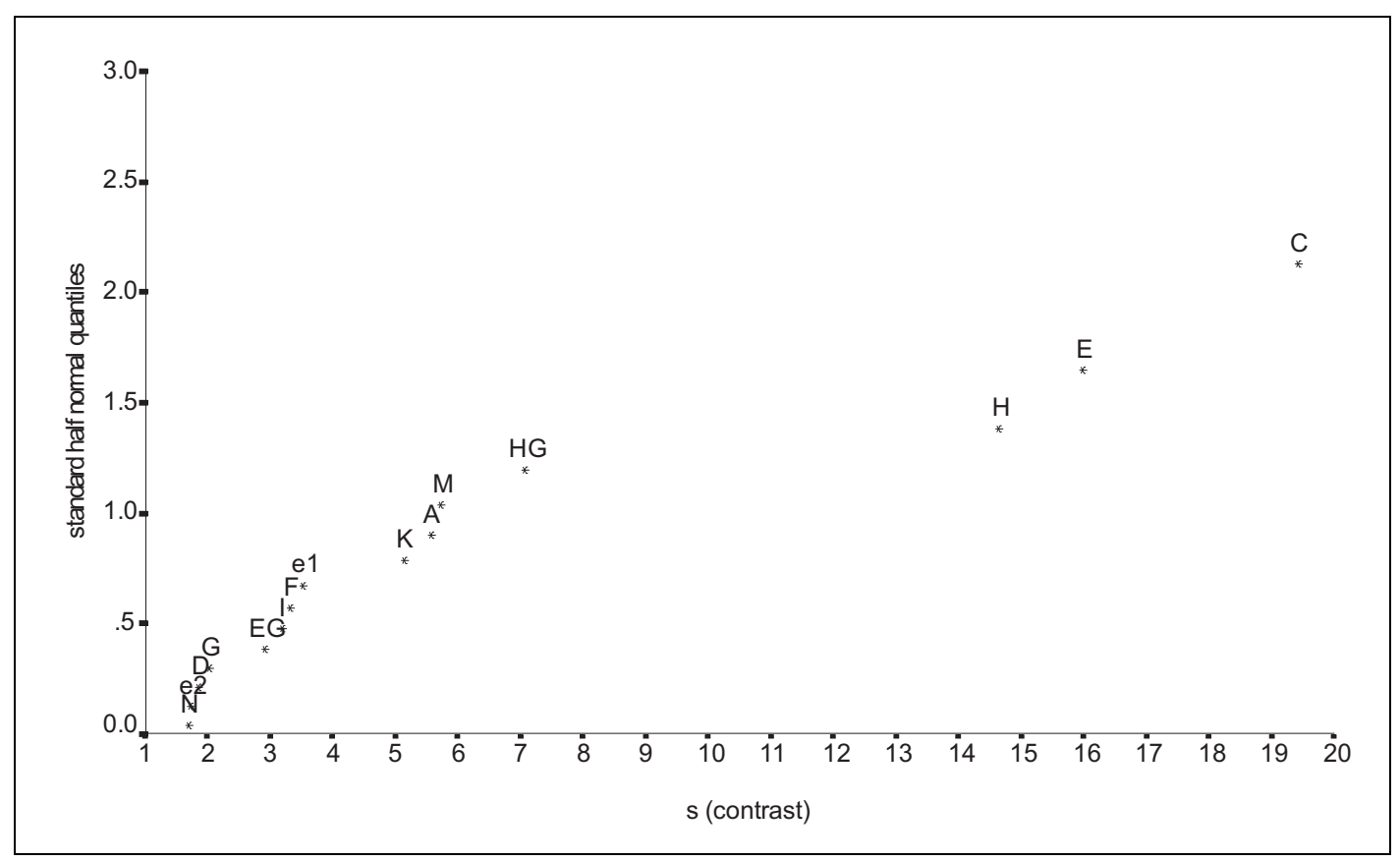

Figure 6: Half Normal Plot 
and the results could be repeated. After discussing and interpreting the results of all the other response variables the engineers tried to find a total response variable weighting the different response variables from the costumer's point of view. This was the starting point for the next step of product improvement.

Experimental design can be a very helpful tool in designing and developing processes. It can help to avoid 'dead ends' in the developing process saving time and money and to learn about product properties and processes in general. Taguchi's philosophy and his way of making design of experiments applicable in the industrial practice was an important step to quality. Although Taguchi's designs are not new, his philosophy and his way of opening the world of experimental design to the engineers also led to a revival of all the well known classic methods of design of experiments.

Concerning this project it has to be said that if professional statistical help was included right from the beginning on this would have led to other designs with easier interpretable aliasing structures and a better understanding in general.

\section{References}

C. Daniels. Use of half normal plots in interpreting factorial two-level experiments. Technometrics, 1, 1959.

J. Krottmaier. Versuchsplanung: Der Weg zur Qualität des Jahres 2000, volume 1. Verlag Industrielle Organisation Zürich, Verlag TÜV Rheinland, first edition, 1990.

R.V. Lenth. Quick and easy analysis of unreplicated factorials. Technometrics, 4, 1989.

D.C. Montgomery. Design and Analysis of Experiments. Wiley, third edition, 1991.

G. Taguchi. System of Experimental Design, volume 1 and 2. UNIPUB/Kraus International Publications, 1988. 3rd printing.

D.A. Zahn. An empirical study of the half normal plot. Technometrics, 2, 1975a.

D.A. Zahn. Modifications of and revised critical values for the half normal plot. Technometrics, 2, 1975b.

Authors' addresses:

DI. Petra Rodiga-Laßnig

DI. Dr. Klemens Fuchs

Institut für Angewandte Statistik und Systemanalyse

JOANNEUM RESEARCH Forschungsgesellschaft mbH

Steyrergasse $25 \mathrm{~A}$

A-8010 Graz

E-mail: petra.rodiga-lassnig@joanneum.ac.at klemens.fuchs@joanneum.ac.at 